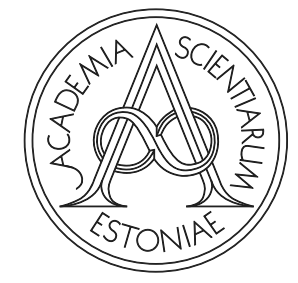

Proceedings of the Estonian Academy of Sciences, $2021,70,4,493-499$

https://doi.org/10.3176/proc.2021.4.17

Available online at www.eap.ee/proceedings

MATERIALS
ENGINEERING

\title{
Chemically bonded PA66-PTFE-oil-cb composites as novel tribologically effective materials: Part 2
}

\author{
Thanh-Duong Nguyen a,b*, Michaela Gedan-Smolka ${ }^{a}$, Lionel Simo Kamgac ${ }^{\mathrm{c}}$, Bernd Sauer ${ }^{\mathrm{c}}$, \\ Stefan Emrich ${ }^{\mathrm{d}}$, Michael Kopnarski ${ }^{\mathrm{d}}$ and Brigitte Voit ${ }^{\mathrm{b}}$ \\ ${ }^{a}$ Leibniz-Institut für Polymerforschung Dresden e. V., Hohe Str. 6, 01069 Dresden, Germany \\ ${ }^{\mathrm{b}}$ Faculty of Chemistry and Food Chemistry, Technische Universität Dresden, Dresden, Germany \\ ${ }^{\mathrm{c}}$ Institute of Machine Elements, Gears and Transmissions (MEGT), Technische Universität Kaiserslautern, Gottlieb-Daimler-Straße 42, \\ 67663 Kaiserslautern, Germany \\ d Institute of Surface and Thin Film Analysis (IFOS), Trippstadter Str. 120, 67663 Kaiserslautern, Germany
}

Received 18 June 2021, accepted 29 June 2021, available online 9 November 2021

(C) 2021 Authors. This is an Open Access article distributed under the terms and conditions of the Creative Commons AttributionNonCommercial 4.0 International License (http://creativecommons.org/licenses/by-nc/4.0/).

\begin{abstract}
Polytetrafluoroethylene (PTFE) exhibits excellent non-stick properties and a very low coefficient of friction under tribological stress, but it is incompatible with almost all other polymers. In the first part of this study, we presented the generation of the novel tribological material based on unsaturated oil, radiation-modified PTFE and Polyamide 66 (PA66). To get a better understanding of the chemical properties and chemical composition of the compounds, the PA66-PTFE-oil-cb (chemically bonded) compounds were examined by differential scanning calorimetry (DSC) and Fourier-transform infrared spectroscopy (FTIR). In this part, the mechanical properties of the compounds are compared with plain PA66 and PA66-MP1100-cb. The tribological investigation was carried out using the block-on-ring tribometer. It was detected that the mechanical properties of PA66-PTFE-oil-cb with $20 \mathrm{wt} \%$ PTFE-oil-cb only show slight differences compared to PA66, but the tribological properties of the compounds were significantly improved through chemical coupling between the three components.
\end{abstract}

Key words: PA66-PTFE-oil-cb compounds, reactive extrusion, chemical coupling, mechanical properties, dry lubricants.

\section{INTRODUCTION}

PTFE offers excellent tribological properties in a wide temperature range $\left(-250^{\circ} \mathrm{C}\right.$ to $\left.+260^{\circ} \mathrm{C}\right)$. However, PTFE exhibits poor mechanical properties and has low adhesion to metal surfaces [1]. Contrary to the chemical stability of PTFE, it is highly sensitive to high-energy radiation. Compared with PTFE, polyamide has very good mechanical properties on the one hand, but it has a high coefficient of friction against steel on the other hand. PTFE itself can be modified by using high-energy radiation to obtain persistent perfluoroalkyl (peroxy) radicals and functional groups (COF and $\mathrm{COOH})[2,3]$. There are two

\footnotetext{
* Corresponding author, nguyen@ipfdd.de
}

approaches to link radiation-modified PTFE to other polymers. One method is the modification via persistent peroxyalkyl radicals and the other route is using the generated functional groups $(\mathrm{COOH}$ and $\mathrm{COF})$. The persistent perfluoroalkyl (peroxy) radicals can be used to form the covalent bond with other polymers/monomers via radical addition reaction [4]. In this study, several olefinic oil types were used, which contain at least one $\mathrm{C}=\mathrm{C}$ double bond and different functional end groups. The olefinic oil molecules can be covalently bonded to radiation-modified PTFE via radical reactions, and the oil functional end groups can generate a variation in affinity to the metal surface. The $\mathrm{COOH}$ functional groups of radiation-modified PTFE can be used to create a covalent bond with polyamide by transamidation reaction, at the 
same time the compatibility between PTFE and the polyamide can be improved [5]. The manufacture and characterization of the compounds based on radiation-modified PTFE, selected oil types and PA66 were presented in the first part of this study [6]. In this research, to illustrate the influence of oil on the mechanical properties of the PA66-MP1100-oil-cb compounds, the mechanical and tribological properties of PA66-MP1100-oil-cb were investigated and compared to the reference materials (PA66-MP1100-cb and the origin PA66). For the mechanical testing, the compound was injection moulded to multipurpose test specimens according to ISO 3167 standard (Fig.1), and subsequently tensile stress, strain at break, the modulus of elasticity, and the Charpy notched impact strength were tested as well. For the tribological testing, the material extrudates were processed by injection moulding and were manufactured in pins with a width of $10 \mathrm{~mm}$ and a working length of $3 \mathrm{~mm}$ afterwards. Finally, the tribological behaviour of the compounds was investigated by a block-on-ring test rig.

\section{EXPERIMENTAL AND METHODS}

\subsection{Materials and reactive extrusion}

The materials were processed in two steps. During the first step, the four different oil types [methyl oleate (MO), oleyl alcohol (OA), oleic acid (OES), and oleyl amine (OAMIN)] were chemically bonded to radiation-modified PTFE (MP1100, Chemours, US) through solid-phase reactive extrusion by using HAAKE Rheomex PTW 16/25 twin-screw extruder (Thermo Fisher Scientific, Germany). MP1100 is radiation-modified PTFE emulsion

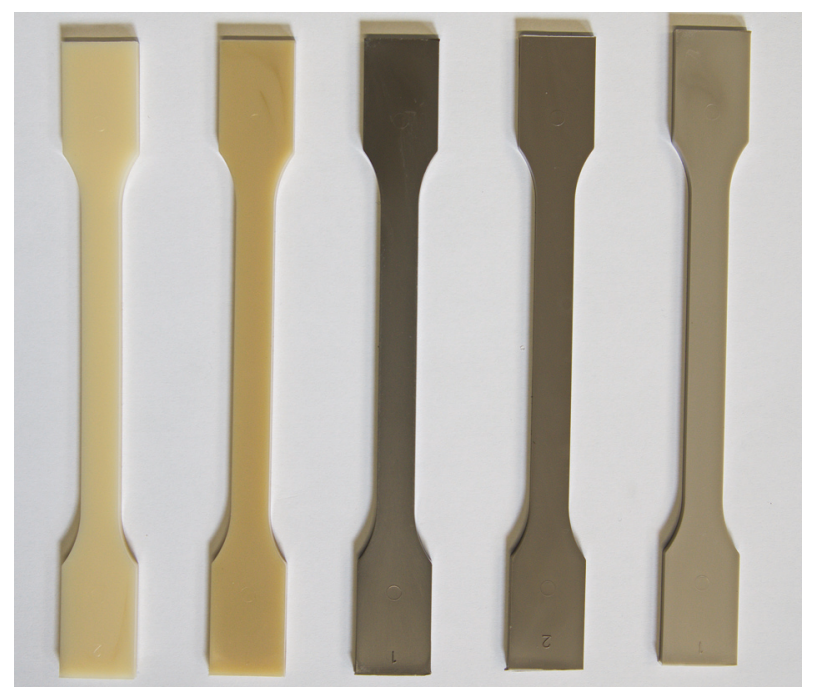

Fig. 1. Multipurpose test specimens according to ISO 3167. polymer and was used in the form it was available. The ratio of MP1100/oil was 10/90 $\mathrm{wt} \%$. The maximum processing temperature was $170{ }^{\circ} \mathrm{C}$. After the first extrusion, the MP1100-oil-cb compound was cooled, pulverized, and then used to couple with PA66 (Technyl A205F, Solvay Engineering Plastics, Germany). In this research the MP1100-oil-cb and PA66 were dosed in a ratio 20/80 wt $\%$ and processed by Leistritz ZSE 27 MAXX twin-screw extruder (Leistritz Extrusionstechnik GmbH, Nürnberg, Germany) in melt. The process temperature was $330{ }^{\circ} \mathrm{C}$. Theoretically, the final sample contains $80 \mathrm{wt} \%$ PA66, $18 \mathrm{wt} \%$ MP1100 and $2 \mathrm{wt} \%$ oil.

\subsection{Injection moulding}

In order to determine the mechanical properties and tribological properties of the compounds, multipurpose test specimens [according to ISO 3167 standard method (Fig. 1)] and semi-finished products (Fig. 2) were prepared by injection moulding (Allrounder $420 \mathrm{C}$, Arburg, Germany) at $350{ }^{\circ} \mathrm{C}$.

\subsection{Mechanical testing}

For the mechanical testing, tensile tests were carried out according to the standard testing method DIN EN ISO 527-2/1BA/1-50 (ZwickRoell 1456 universal testing machine, ZwickRoell GmbH, Germany). The notched impact bending test and the Charpy notched impact strength tests were performed according to the DIN EN ISO 179/1EA standard using a ZwickRoell pendulum impact tester 4J.

\subsection{Tribological testing}

Tribological investigations of the compound materials were carried out on a block-on-ring test rig. Figure 3 shows

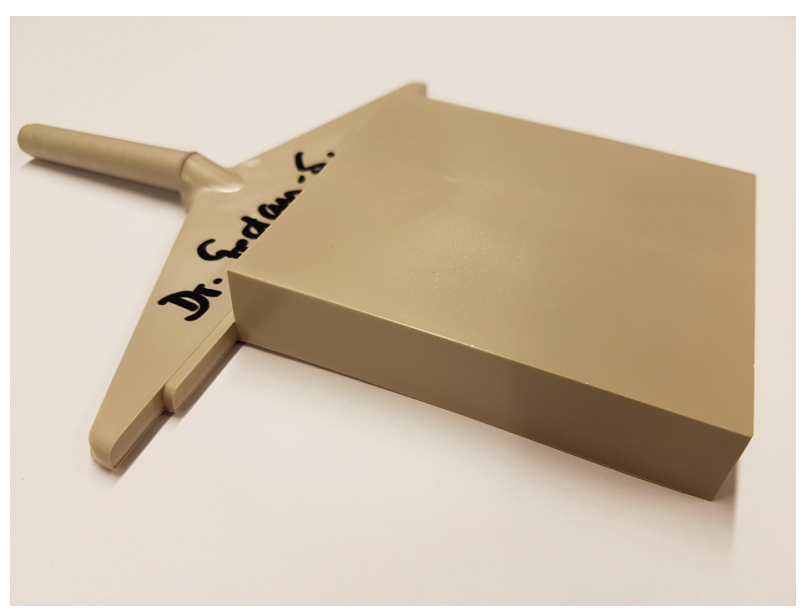

Fig. 2. Semi-finished product. 


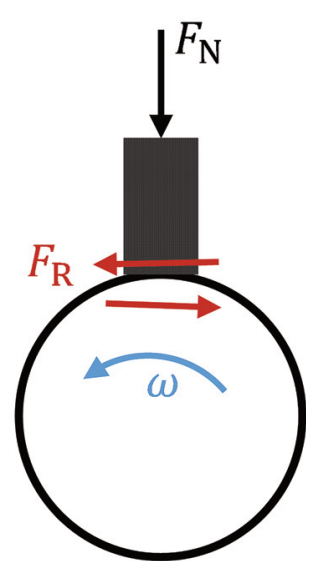

Fig. 3. Scheme of tribological testing.

a scheme of the test configuration. For these experiments, blocks with a width of $10 \mathrm{~mm}$ and a working length of $3 \mathrm{~mm}$ were manufactured from the respective compounds. The blocks were pressed on a running steel disc each. The steel disc made of $16 \mathrm{MnCr} 5$, which was hardened (60 HRC) and ground in the axial direction (with a roughness value of $S a=0.2 \mu \mathrm{m}$ according to DIN EN ISO 25178), has a diameter of $80 \mathrm{~mm}$ and a width of $13 \mathrm{~mm}$. In order to create a uniform pressure distribution between the PA66-MP1100-oil-cb compound blocks and the steel disc, the compounds were ground in the working (rotation) direction to the radius of the steel counter sample.

After the blocks and the steel discs were manufactured, they were cleaned in an ultrasonic bath and dried under the ambient condition in the laboratory (at $20-25{ }^{\circ} \mathrm{C}$ ). For the steel rings, cyclohexane, isopropanol, and acetone were used as the cleaning agents and ethanol was utilized for the PA66-MP1100-oil-cb compounds. The tests were carried out at constant load $(p=5 \mathrm{MPa})$ and constant sliding speed $(u=0.3 \mathrm{~m} / \mathrm{s})$ for $5 \mathrm{~h}$ (approx. $6 \mathrm{~km}$ ). For each test configuration, the measurements were performed three times to determine the statistical certainty.

\section{RESULTS AND DISCUSSION}

\subsection{Results of mechanical testing}

Figure 4 shows that the compound PA66-MP1100-cb has a significantly higher E-modulus compared to the original PA66. This behaviour could be related to the chemical bonding of the compounds, excellent breaking-down ability of the MP1100 as well as the great distribution of its particles in the PA66 matrix.

Furthermore, according to the literature [7], the crystalline proportion of the compounds was increased through the reactive extrusion and injection moulding process.

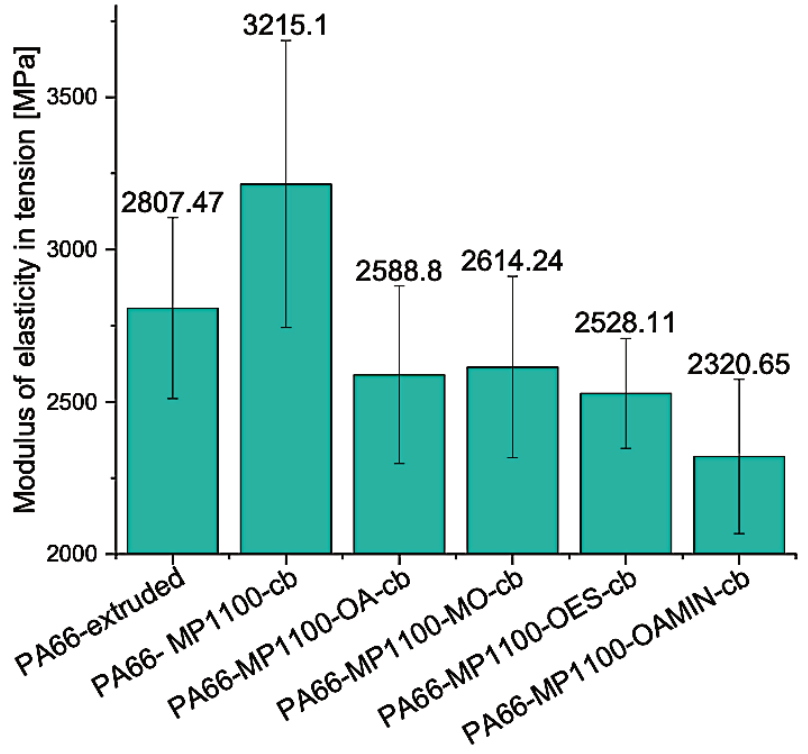

Fig. 4. Modulus of elasticity in tension.

In our research, MP1100 micro-powder was covalently chemically bonded to the PA66 matrix, at the same time the compatibilization between MP1100 and PA66 was increased. The compounds with chemically bonded oil (PA66-MP1100-OA-cb, PA66-MP1100-MO-cb, PA66MP1100-OES-cb, PA66-MP1100-OAMIN-cb) generally show lower elasticity values than the original PA66 and the MP1100-modified PA66. This is in fact due to the twostep extrusion process. In the first extrusion step, it was expected that the bonding between oil molecules and MP1100 would proceed by radical reactions selectively. However, the PA66-MP1100-OAMIN-cb compound showed the lowest modulus of elasticity compared to the other types of MP1100-oil-cb. This is due to the fact that the $\mathrm{NH}_{2}$-end-group of oleyl amine reacted with the carboxylic group of the MP1100 during the first extrusion step as well, resulting in a much higher coupling degree between oil and MP1100, as it was detected by FT-IR-spectroscopy. During the second extrusion step of PA66 in the melt state, there were only a few $\mathrm{COOH}$ functional groups of MP1100 still available for the chemical reaction that led to a very low bonding of PA66. Thus, MP1100OAMIN-cb is mainly physically distributed in the PA66 matrix.

The reactive compounding of PA66 with $20 \mathrm{wt} \%$ of MP1100 has reduced the tensile strength values by approximately $10 \%$ as opposed to the plain PA66. The chemically bonded PA66-MP1100-oil-cb compounds with several oil types show only a slight additional decrease effect on the tensile strength (Fig. 5).

Figure 6 provides the result of tensile stress at break. It is obvious that in the case of PA66-MP1100-cb, the 


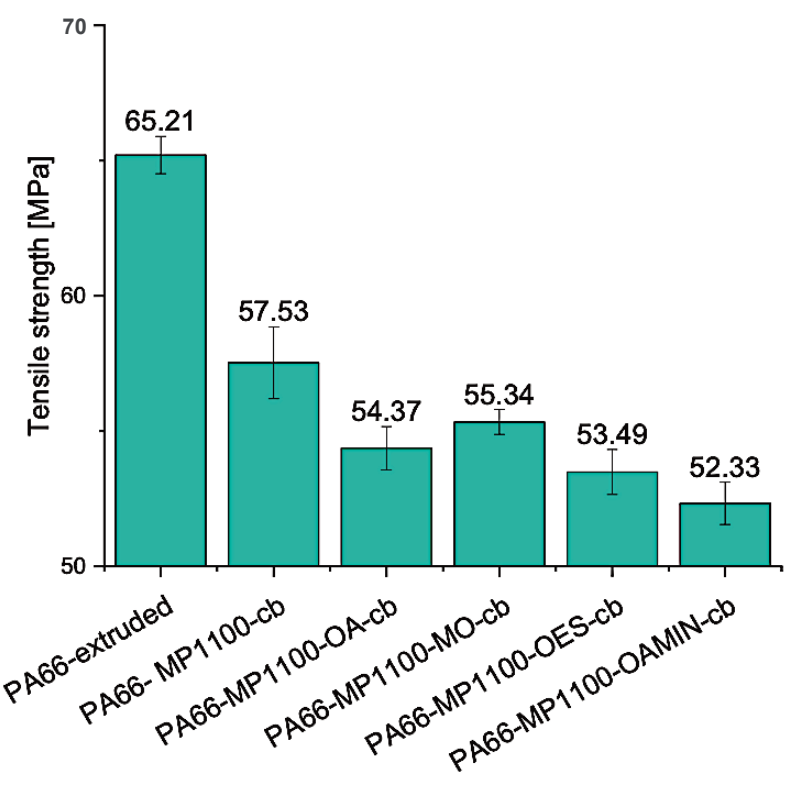

Fig. 5. Tensile strength.

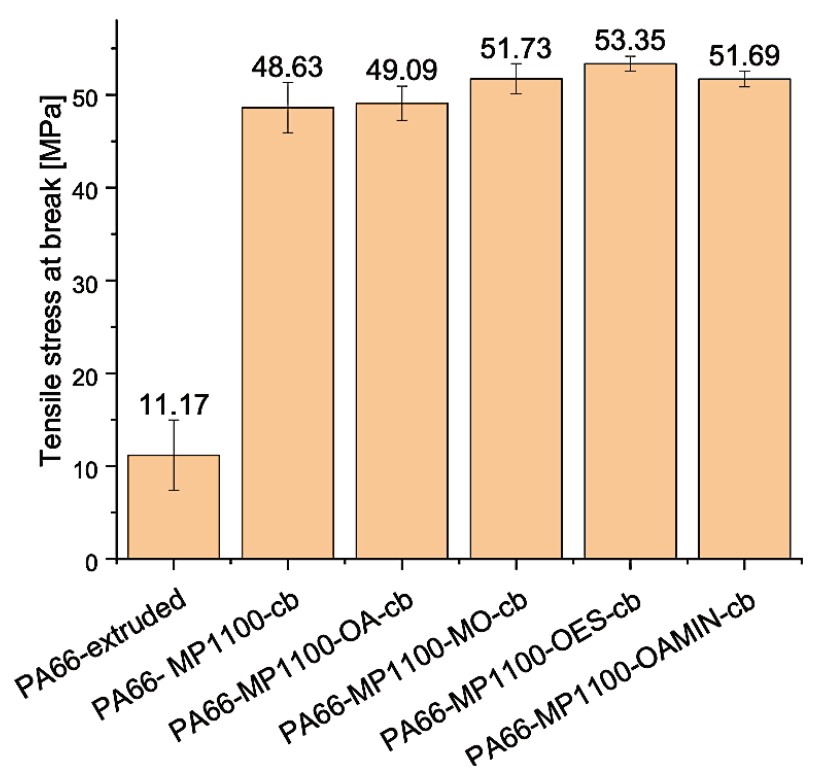

Fig. 6. Tensile stress at break.

value is four times higher than the value of the plain PA66. The chemically bonded oil increased the tensile stress at break only slightly compared to PA66-MP1100-cb. It is assumed that the oil content $(2 \mathrm{wt} \%)$ is too low compared to PA66 and MP1100 (80 wt\% and $18 \mathrm{wt} \%$ ) to get a further significant effect. On the other hand, the values of tensile strain at break decreased drastically when PA66 was compatibilized with MP100 (Fig. 7). In the case of PA66-MP1100-cb, the values decreased by approximately

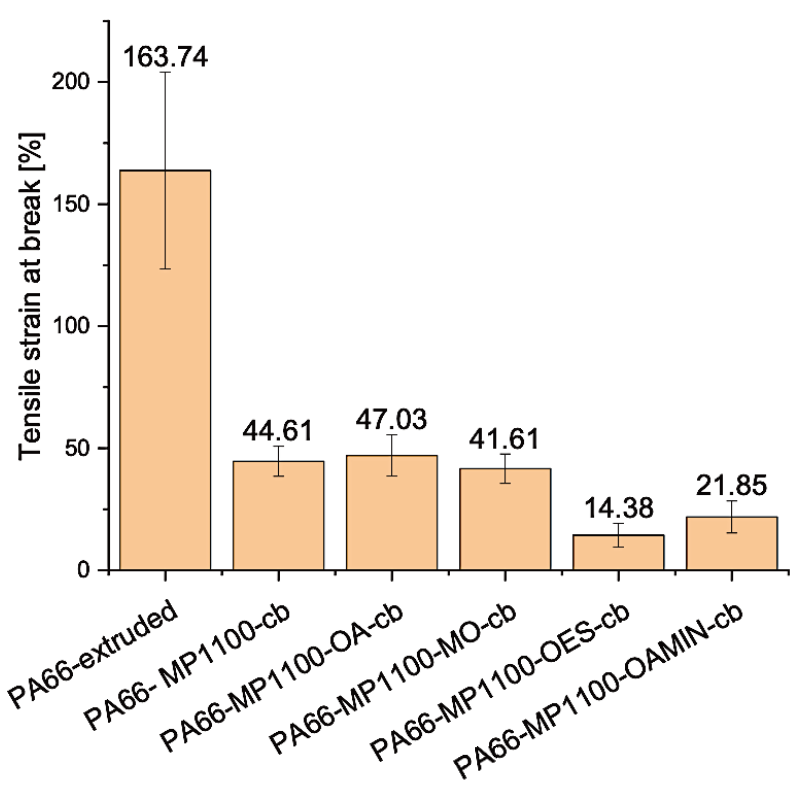

Fig. 7. Tensile strain at break.

$70 \%$. Concerning the various oils, it was detected that for PA66-MP1100-OA-cb and PA66-MP1100-MO-cb, there was almost no sign of any influence of chemically bonded oil on the tensile strain at break. Hypothetically it can be assumed that there is a transamidation reaction between excess oleic acid and PA66, so that the probability that MP1100 reacts with PA66 could be reduced. The result is that the compatibility between MP1100 and PA66 is lower with the presence of oleic acid, so the tensile strain at break is reduced.

In the case of Charpy notched impact strength (Fig. 8), the compound PA66-MP1100-cb has the highest value, and this is approx. $40 \%$ more than the value of the plain PA66. As realized before in regard to other combinations, this behaviour should be the result of chemical bonding as well as much better breaking-down of MP1100 aggregates and distribution of MP1100 particles in the PA66 matrix. The Charpy notched impact strength of the other compounds in the presence of more or less bonded oil is lower than that of PA66-MP1100-cb, as the oil interferes with the compatibilization between PA66 and MP1100. The Charpy notched impact strength values decrease in the following order:

PA66-MP1100-cb>PA66-MP1100-OA-cb >PA66-MP1100MO-cb>PA66-MP1100-OAMIN-cb>PA66-MP1100-OES$\mathrm{cb}$.

\subsection{Result of tribological testing}

Figure 9 demonstrates the curve of the coefficient of friction $(\mathrm{COF})$ and the disc temperature $(\vartheta$ Steel) when 


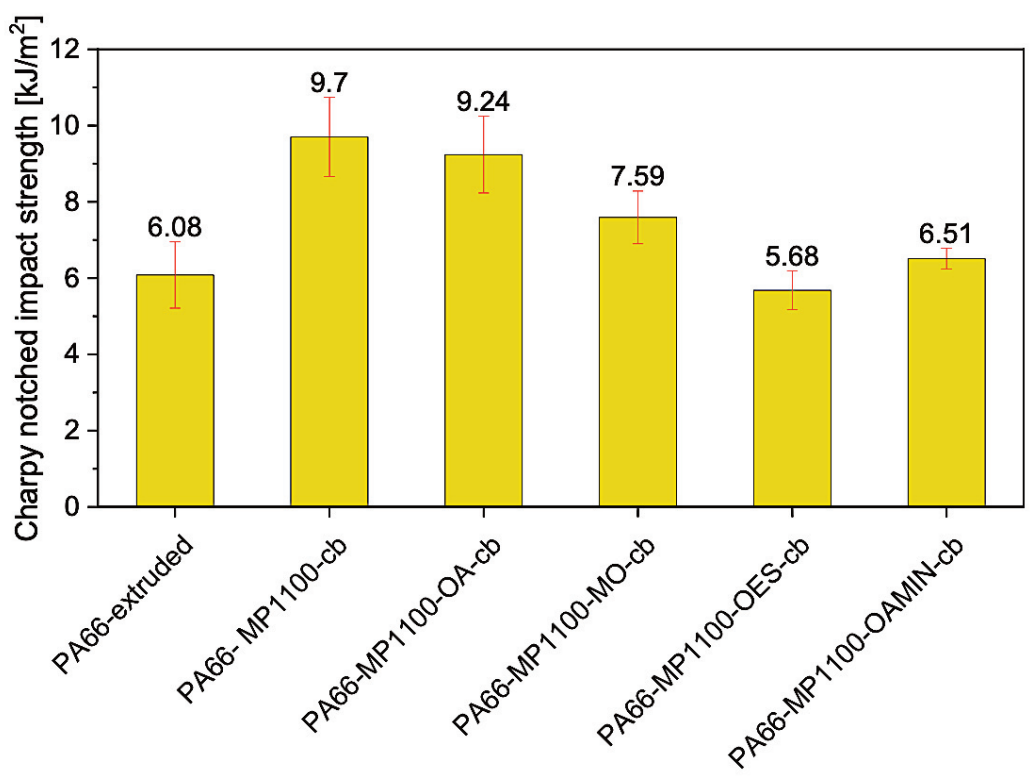

Fig. 8. Charpy notched impact strength.



Fig. 9. Characteristic behaviour of the coefficient of friction and the temperature of PA66-MP1100-OES-cb.

PA66-MP1100-OES-cb is in contact with the steel disc, as an example for the PA66-MP1100-oil-cb materials. The temperature was measured approximately $2 \mathrm{~mm}$ below the contact surface, which means that the recorded temperature is therefore lower than the current contact temperature. For each compound, three measurements were carried out. It can be seen that up to a sliding distance of approx. $1 \mathrm{~km}$, the coefficient of friction and the temperature increase rapidly in the running-in phase. After- wards, the coefficient of friction gradually decreases again and reaches a more or less constant value after a sliding distance of approx. $4 \mathrm{~km}$. This behaviour of the coefficient of friction can be attributed among other things to the temperature dependency of the material parameters of the compounds, which influences the adhesive and the deformation parts of the friction forces.

In the first part of this study, the friction behaviour of PA66-MP100-cb, PA66-MP1200-cb, and PA66-MP1600-cb 
was investigated and compared to the original PA66. It was determined that the friction coefficient of the PA66MP1100-cb compound has a relatively lower coefficient of friction, compared to other samples. For this reason, the sample with MP1100 was chosen to combine with various types of oil. After the chemical compatibilization with $20 \mathrm{wt} \%$ MP1100, the COF of the PA66-MP1100-cb compound was reduced to $0.37 \pm 0.02$ (in comparison to unmodified PA66 with $0.57 \pm 0.02$ ). Figure 10 shows the influence of the several oil types on the friction behaviour of PA66-MP1100-oil-cb and the heating of the counter body. The values of the coefficient of friction and temperature indicated below correspond to their mean values from a sliding distance of $5 \mathrm{~km}$ upwards, see Fig. 9. Additionally, Fig. 10 shows the volume wear of the compounds, calculated with the determined loss of mass at the end of the respective tests using the determined density of the compounds from Table 1. It can be seen that in the load range investigated, the oil type methyl oleate displays a more favourable friction behaviour in contact with the steel disc.

\section{CONCLUSIONS AND OUTLOOK}

Although only $2 \mathrm{wt} \%$ of oil is chemically bonded in PA66MP1100-oil-cb, its effect is visible in mechanical and tribological properties. The elasticity of the compound with chemically bonded oil is generally lower compared to PA66-MP1100-cb, especially for the compound with oleyl amine (reduced approx. 28\%). The Charpy notched impact strength values of the compounds decrease in the following order:

PA66-MP1100-cb>PA66-MP1100-OA-cb >PA66-MP1100MO-cb>PA66-MP1100-OAMIN-cb>PA66-MP1100-OEScb.

The friction behaviour of chemically bonded PA66MP1100-oil-cb is generally better than for PA66-MP1100$\mathrm{cb}$, among which the compound containing methyl oleate shows the best result.

In the future research:

- We strive for single-step reactive extrusion for the producing of the compounds.

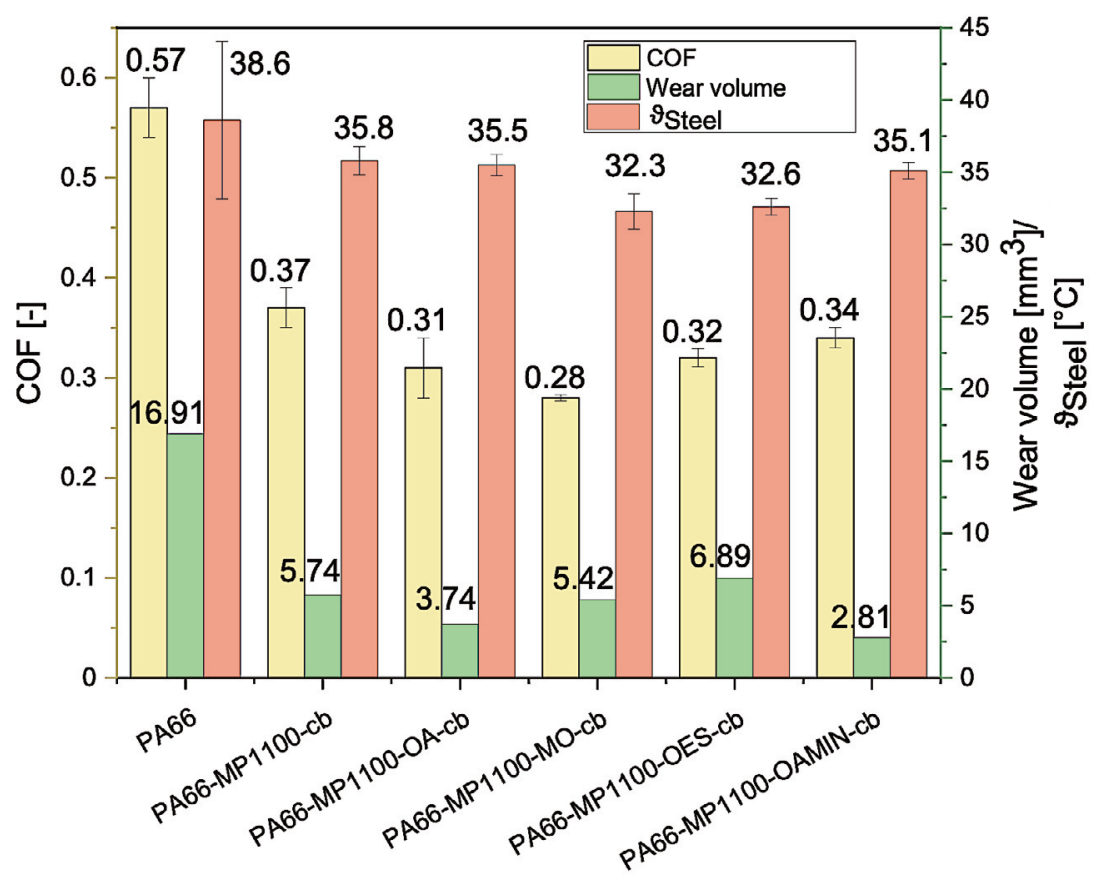

Fig. 10. Influence of oil type on the friction behaviour of the PA66-MP1100-oil-cb compounds.

Table 1. Density of the compounds

\begin{tabular}{c|c|c|c|c|c}
\hline Compound & $\begin{array}{c}\text { PA66-MP1100- } \\
\mathrm{cb}\end{array}$ & $\begin{array}{c}\text { PA66-MP1100- } \\
\text { OA-cb }\end{array}$ & $\begin{array}{c}\text { PA66-MP1100- } \\
\text { MO-cb }\end{array}$ & $\begin{array}{c}\text { PA66-MP1100- } \\
\text { OES-cb }\end{array}$ & $\begin{array}{c}\text { PA66-MP1100- } \\
\text { OAMIN-cb }\end{array}$ \\
\hline Density $\left[\mathrm{g} / \mathrm{cm}^{3}\right]$ & 1.2470 & 1.2435 & 1.2519 & 1.2472 & 1.2515
\end{tabular}


- We use other oil types containing phosphate functional groups to increase the affinity of the compound to the metal surface.

- The influence of the transferred tribo-film on the steel disc will be investigated in the steel/bronze contact.

\section{ACKNOWLEDGEMENTS}

The authors thank the Deutsche Forschungsgemeinschaft for financial support, T. Schmidt for carrying out numerous experiments, D. Pahlitzsch for the extrusion, A. Scholze and C. Lehmann for the injection moulding and H. Scheibner for the mechanical testing. The publication costs of this article were covered by the Estonian Academy of Sciences and Tallinn University of Technology.

\section{REFERENCES}

1. Kaiser, W. Kunststoffchemie für Ingenieure. Karl Hanser Verlag GmbH \& Co. KG, 2011.
2. Lunkwitz, K., Lappan, U. and Lehmann, D. Modification of fluoropolymers by means of electron beam irradiation. Radiat. Phys. Chem., 2000, 57(3), 373-376.

3. Lehmann, D. Modified PTFE-solid lubricants and method of producing and using them. German Patent DE102014225672A, 16 June 2016.

4. Lehmann, D. Oil-modified PTFE-solid lubricants and the method of their producing. German Patent DE102014225671, 16 June 2016.

5. Pompe, G., Häußler, L., Adam, G. A., Eichhorn, K. J., Janke, A., Hupfer, B. and Lehmann, D. Reactive polytetrafluoroethylene/polyamide 6 compounds. II. Study of the reactivity with respect to the functionality of the polytetrafluoroethylene component and analysis of the notched impact strength of the polytetrafluoroethylene/polyamide 6 compounds. J. Appl. Polym. Sci., 2005, 98(3), $1317-1324$.

6. Nguyen, T.-D., Gedan-Smolka, M., Simo Kamga, L., Sauer, B., Emrich, S., Kopnarski, M. and Voit, B. Chemical bonded Oil-PTFE-PA66-cb composites as novel tribologically effective materials: Part 1. Solid State Phenom., 2021, 320, 113-118.

7. Fornes, T. and Paul, D. Crystallization behavior of nylon 6 nanocomposites. Polymer, 2003, 44(14), 3945-3961.

\section{Kovalentselt seotud PA66-PTFE-õli baasil hübriidmaterjalid kui uudsed triboloogiliselt efektiivsed materjalid: 2. osa}

\section{Thanh-Duong Nguyen, Michaela Gedan-Smolka, Lionel Simo Kamga, Bernd Sauer, Stefan Emrich, Michael Kopnarski ja Brigitte Voit}

Polütetrafluoroetüleen (PTFE) on mittekleepuv väga madala hõõrdeteguriga polümeer, mis on aga ühitamatu peaaegu mistahes muu polümeeriga. Antud uuringu esimeses osas on kirjeldatud uudse triboloogilise materjali arendamist küllastumata õli, kiirgusmodifitseeritud PTFE ja polüamiidi 66 (PA66) baasil. Et paremini mõista materjali keemilisi omadusi ja keemilist koostist, uuriti PA66-PTFE-õli hübriidmaterjale, kasutades diferentsiaalset skaneerivat kalorimeetriat ja Fourier' infrapunaspektroskoopiat. Muudetud hübriidmaterjalide mehaanilisi omadusi võrreldakse tavaliste materjalide PA66 ja PA66-MP1100-õli omadustega. Triboloogilisi uuringuid viidi läbi klots-ketta-vastu tüüpi tribomeetril. PA66PTFE-õli hübriidmaterjali, mis sisaldab 20 massi\% õlimolekulidega seotud PTFE-d, mehaanilised omadused peaaegu ei erine PA66 mehaanilistest omadustest, samal ajal hübriidmaterjalide triboloogilised omadused on märgatavalt paranenud tänu keemilistele sidemetele komponentide vahel. 